THEORIA ET HISTORIA S CI EN TIA RUM, V O L . VII, № 2

Ed. Nicolas Copernicus University 2003

Robert Langs, M.D.*

\title{
The Evolution of The Unconscious Processing Systems of the Human Mind
}

\section{Introduction}

The human mind has evolved in a most peculiar fashion. It's currently agreed that the mind evolved into specialized units called modules, collections of mental capacities devoted to broad, but basic adaptive functions like perceiving, socializing, navigating in the physical world, and the like (Cosmides \& Tooby, 1992, Donald, 1991, Gazzaniga, 1992, Langs, 1996a,b, Mithen, 1996, Plotkin, 1994, Slavin \& Kriegman, 1992, Tooby \& Comides, 1990).

Studies from an adaptive viewpoint (Langs, 1996a,b, 1997, 1998, 1999) indicate that in respect to coping with highly charged environmental challenges or traumas, the mind has evolved two basic systems:

The emotional mind, which generates affective responses to stressful events, hormonebased psychological responses that then mobilize bodily and mental resources for coping; and

The emotion-processing mind, which copes mentally with emotionally charged events and their consciously and unconsciously experienced meanings.

The emotion-processing mind is, itself, a two-system module. There's a conscious system that is attached to awareness and deals with undisguised perceptions using conscious thinking and intelligence, and a deep unconscious system that has no direct access to awareness, but is able to reveal the nature of its unconscious perceptions and the processing of these perceptions by sending

* Address for correspondence: Dr. R. J. Langs, 133 West 72nd Street, Suite 304, New York, NY 10023, USA. Email: RJ3321@aol.com 
to the conscious mind encoded messages in the form of dreams and other types of narratives that enter awareness in disguise. The deep unconscious system has two major subdivisions: a deep unconscious wisdom/processing subsystem and a fear/guilt subsystem. The_former is an adaptive unconscious intelligence and the latter a system of ethics and morality.

These realizations have emerged through a new paradigm of psychoanalysis called the communicative/adaptive approach, to which I now turn.

\section{The adaptive/communicative approach}

Both the Freudian and Jungian views of the mind are lacking in a comprehensive understanding of deep unconscious adaptive processing. The Freudians allow for unconscious ego and superego functions, but do so in general terms and do not consider these processes as efforts to cope with the consciously and unconsciously perceived meanings of moment-to-moment events, including those that occur in the course of a psychotherapy session. Instead their prime concern is with patients' unconscious fantasies and memories-their transferences-as aroused in the interaction with the therapist (Slavin \& Kriegman, 1992).

For their part, the Jungians assign a broad, unconscious intelligence to dreams, but also do so without examining moment-to-moment efforts at coping (Maiden- baum, 1998). Both of these psychoanalytic approaches fail to see adapting to environmental events and their conscious and unconscious ramifications as the primary function of the emotionprocessing mind, nor do they have an appreciation of the intricacies of the highly complex adaptive module that has evolved for this specific function-the emotion-processing mind.

The adaptive/communicative approach to the human mind views the emotionprocessing mind as fundamentally adaptive in nature. It proposes that the activities of the emotion-processing mind are triggered by specific emotionally charged or traumatic events and that human emotional-related communications and behaviors can be properly understood only in light of these evocative events. The detailed, clinical investigation of the conscious and unconscious processing of specific triggering events or triggers reveal a great deal about the design of the emotionprocessing mind that has not been previously unrecognized.

Three unexpected and seemingly inexplicable features of this mental module emerged from these studies and there was little progress in the effort to understand them until there was a turn to the science of evolution and an attempt to develop a deep understanding of the likely evolutionary history of the emotion-processing mind (Langs, 1996a,b).

The first of these puzzling features is the finding that the conscious system is configured in a highly defensive fashion that involves the extensive use of 
obliteration and denial in response to triggering events. This means that humans are inclined to be quite unaware of many of the most powerful and affecting meanings of emotionally charged events that impact on them, and that, in addition, many such incidents go entirely unregistered consciously as well.

This phenomenon implies a move toward knowledge reduction vis-a-vis the environment, a most unusual evolutionary course in that the general rule is for natural selection to favor mutations that enhance contact with and adaptation to environmental events. The challenge, then, was to forge an evolutionary scenario that could account for the extreme defensiveness of the conscious system and to determine the selection pressures that were involved.

A second problem arose with the discovery that the deep unconscious system is not only capable of perceiving without awareness, but also able to process the implications of the events and psychological meanings that do not register consciously. In studying these processing capabilities, it was found that deep unconscious intelligence is remarkably astute and adaptively effective, far more so than conscious intelligence in respect to emotionally charged triggers. Furthermore, as noted, the results of these processing efforts do not enter awareness directly, but solely through disguised (encoded) narratives. As a result, the extremely helpful insights and directives of the deep unconscious system are unable to favorably influence our adaptive decisions and behaviors-the conscious mind is at the mercy of other, more disruptive, unconscious pressures (see below).

The only way around this natural communicative barrier is to engage in a process called trigger decoding, in which disguised narrative messages like dreams are decoded in light of their evocative triggers. But humans do not spontaneously engage in this decoding process, preferring instead to use a highly intellectual and defensive approach to dreams in which they extract obvious implications from their surface images or propose symbolic interpretations for the themes involved. These efforts do not take adaptation-evoking triggers, deep unconscious meaning, and deep unconscious coping efforts into account.

The questions that needed to be answered through an evolutionary scenario, then, were these:

Why are the most effective human responses to emotionally charged stimuli generated by the unconscious rather than the conscious mind?

Why aren't these highly adaptive reactions available to favorably influence conscious efforts at adaptation and coping?

And given that messages from our deep unconscious intelligence can be decoded in light of their triggers, why are humans so reluctant to engage in this type of decoding process?

The last mystery emerged with the discovery of a deep unconscious fear/ guilt system and the phenomenon of deep unconscious guilt. Thus, it was found that the deep unconscious mind possesses a universal set of behavioral standards, 
a morality that defines and validates an ideal framework for relating and interacting-an optimal set of rules, frames, and boundaries (Langs, 1998). Adherence to these standards evokes unconscious validation, while departures are not validated, but are, instead, unconsciously perceived as harmful to oneself and others. In addition, it emerged that violations of this universal code of behavior creates deep unconscious guilt, which, in turn, has strong effects on conscious adaptations in that it creates unwitting pressures toward self-punitive decisions and actions.

As for the fear aspect of this system, there were indications that death anxiety played a role in its operation and that in some way, the fears evoked by death were a factor in the defensiveness of the conscious system (Langs, 1997, 1999).

The main questions for evolution here were: Why does deep unconscious guilt and fear affect the adaptive choices of the conscious mind while unconscious wisdom does not? And why does guilt and the fear of death operate to a significant extent outside of awareness and with such a strong effect on human behavior?

\section{A clinical illustration}

A brief vignette will serve to clarify the discussion to this point.

Mrs. Jenkins is in psychotherapy with Dr. Benton. She begins a session with a dream in which her brother is fondling her breasts. Associating to the dream, she recalls an incident when she was an adolescent in which her brother had gotten into bed with her and tried to seduce her. There have been times in the past, she adds, when Dr. Benton has the kind of look on his face that her brother had when he was in bed with her. That's a really stupid thought, isn't it? Anyhow, she remembers telling her brother that she'd never talk to him again if he didn't get himself under control.

For most dynamic psychotherapists, this excerpt would be seen as a classical example of a brother transference. That is, the patient's view of Dr. Benton as seductive would be seen as an unconsciously caused distortion based on the early seductive behavior of her brother. This view of the therapist also would be formulated as the patient's projection onto Dr. Benton of her own seductive wishes toward him, based on earlier wishes directed toward her sibling.

All of these formulations and many others are based on the patient's material in and of itself, without consideration of any possible trigger to which the patient is adapting. This way of thinking is based on the theory, proposed by Freudians and Jungians alike, that neuroses are caused by patients' unconscious memories and fantasies. The prevailing idea is that emotional problems stem primarily form the mind in conflict, usually stated as the id in conflict with the superego, as mediated by the ego. This is why therapists who accept this theory examine 
patients' material in isolation: the war is within the patient and the therapist is recruited as a player in this inner battle. This leads in turn to formulations of extracted implications of patients' material such as the highly intellectual interpretation that the Mrs. Jenkin's dream and associations reflect a brother transference and a projection onto Dr. Benton of her own, repressed sexual wishes toward him. In this approach, as noted, adaptation to immediate events, especially to the specific interventions of the therapist, is either not considered at all or is thought of as a minor issue. I call this the weak adaptive position (Langs, 1996a).

In contrast, the adaptive/communicative approach is based on a strong adaptive position that theorizes that adapting consciously and deep unconsciously to immediate environmental events and their meanings is the primary function of the emotion-processing mind (Langs, 1996a). Adaptation is, indeed, the primary function of all organisms and of the minds of all organisms with brains, the sponsor of mental functions (Plotkin, 1994, Slavin \& Kriegman, 1992).

It follows, then, that the most compelling meanings of a two-tiered narrative communication like a dream is discernible only when the trigger for the dream has been identified and the themes of the dream decoded in light of that triggering event. This process of trigger decoding is the only known means of gaining access to the deep unconscious experiences that most powerfully and unconsciously drive emotional life and both its dysfunctions and health. All else, whatever its meaning, is secondary.

Returning to the vignette, the trigger for Mrs. Jenkins dream occurred in the previous session when Dr. Benton inadvertently brushed against her arm as he escorted her from his waiting room to his consultation room. While Dr. Benton felt the touch, Mrs. Jenkin's later material indicated that consciously she had felt nothing. Nevertheless, her dream indicates that she felt (perceived) the contact unconsciously and then processed it with her deep unconscious system intelligence, through which she recognized that physical contact between herself and her therapist has unconscious incestuous meanings.

The sole conscious effect of this unconscious processing is seen in the patient's mentioning a time in the past when the therapist appeared to have a seductive look on his face. On the other hand, the patient was not able to grasp the highly adaptive advice offered by her deep unconscious intelligence-namely, to stop talking to Dr. Benton if he proves to be unable to renounce his seductiveness, an idea that's tantamount to suggesting that she leave the therapy if he doesn't desist. The patient was entirely unaware of this wise advisory

Importantly, the usual interpretation of this material holds the patient accountable for misperceptions of the therapist as seductive and for her incestuous fantasies and wishes. The adaptive/communicative interpretation holds the therapist accountable for an inadvertent seductive act that was motivated 
unconsciously within himself, and sees the patient as being unconsciously perceptive and not distorting her view of the therapist in any manner.

The adaptive viewpoint leads one to formulations that typically are the very opposite of present-day psychoanalytic thinking from any other vantage point. To the extent that the adaptive position is the valid one, it appears that therapists' usual way of formulating and interpreting is, itself, a reflection of the defensiveness and massive use of denial that characterizes the conscious mind.

\section{An adaptive scenario}

Turning to the literature on evolution and adaptation, and making full use of the adaptive approach to psychotherapy, it's possible to propose a scenario with selection pressures and other factors that appears to account for the evolved, present-day design of the emotionprocessing mind.

The story may be thought to begin with the acquisition of language by humans about 150,000 to 200,000 years ago (Bickerton, 1990; Corballis, 1991; Liberman, 1991). Among the countless adaptive advances that fanned out from this remarkable achievement, language gave humans the ability to represent events internally and process them in absentia, to anticipate the future, and to establish a clear sense of individual identity as separate from others. An important further consequence of attaining these capabilities was the explicit, conscious recognition that humans are mortal and eventually must die. The result of this uniquely human, conscious insight was the development of severe existential death anxieties that were readily intensified by death-related events such as illness, injury, loss and the like.

Another explicit conscious capability to arise with language acquisition involved the ability of a humans to recognize the intentions of others, especially fellow humans, to cause them harm both physically and psychologically-and thereby, an intensification of predatory death anxiety. Similarly, their own intention to, or actual acts of, harm directed against others was more extensively realized consciously, but more often than not, these thoughts and inclinations were restricted to unconscious registration (Langs, 1997). In either case, there was the development of predator death anxiety in these situations.

There was, then, in language-based humans an intensification of predatory death anxiety, a fear common to all mindful beings, as well as the creation of two new forms of death anxiety that are exclusively theirs-existential (re: human mortality) and predator (re: harming others).

In addition, language acquisition led to an enormous increase in the complexity of human life and created an overflow of adaptive challenges and other psychological impingements with which the conscious mind was forced to 
cope. There were huge technological advances, including the development of more and more effective weapons of death and destruction, while social structure became highly complex, rules and ethics more complicated, relationships with others more intricate and convoluted, and child rearing more demanding. The list of possible danger situations also grew enormously and all in all, the conscious mind was soon being called on to deal with far more than it could possibly manage. The complexities of human life became overwhelming and the sources of stress, harm and death far outran the newly developed resources of the conscious mind.

It appears, then, that stimulus overload and mounting threats of personal harm and death endangered the survival of humans on both the species and individual levels. The acquisition of language, perhaps the greatest evolutionary advance in the history of living species, was threatening the extinction of this exceedingly gifted line of hominids. The newly emerging, brilliant and inventive, language-based conscious mind was being overwhelmed by its own social and technological advances.

It was in response to these threats to survival that natural selection appears to have favored minds that had the capacity to automatically shunt many traumatic inputs-both events and psychological meanings-to a second system of the mind that operated entirely outside of awareness. Minds capable of unconscious perception, processing, and encoding the results of these efforts (which was necessary because conscious awareness of the anxiety-provoking, dangerous triggering event needed to be spared throughout) survived better than minds without these abilities. And it's this two-system, emotion-processing mind, shaped largely by death anxiety and system overload, that exists today as an evolved feature of all humans.

\section{Some further perspectives}

The automatic unconscious perception of selected events and meanings is the basis of conscious system denial and obliteration. It follows, too, that denial (which is directed mainly against environmental impingements), rather than repression (which is directed mainly against inner-mental fantasies and memories), is the basic psychological defense used by the emotion-processing mind. But while denial spares the mind and individual from being rendered dysfunctional by excessive stress, an enormous price is paid for this protection. There's a severe reduction in our conscious knowledge of environmental events and their most critical meanings, and thereby, a great loss of effective adaptive responsiveness. There is as well a major loss of insight into the most compelling issues in emotional life, a failure to appreciate and cope with the sources of the most 
basic human anxieties and neuroses, support for manic defenses that harm oneself and others, striking impediments to emotional growth, the creation of uninsightful and often harmful forms of psychotherapy, and more broadly, terrible social consequences such as unnecessary murders and wars. Clearly, a psychoanalytic theory that does not grasp the essential features of the emotion-processing mind and its evolutionary history cannot foster social growth and personal and international peace.

By evolved design, the emotion-processing mind responds differently to each of the three forms of death anxiety. Existential death anxiety activates denial responses in both behavior and mind, the latter a factor in the deep unconscious fear subsystem which activates denial mechanisms.

Predatory death anxiety mobilizes both physical and mental resources, and tends to shut down the deep unconscious subsystem in order to facilitate a maximal conscious system response.

Finally, predator death anxiety activates conscious and deep unconscious guilt in response to both the thought and act of harming others. There is in all humans a deep and abiding need to harm others, physically and/or psychologically, for a myriad of reasonse.g., the need for property, food and shelter; the wish to deny personal vulnerabilities and death; jealousy and envy; and acts of retaliation and vengeance. The deep unconscious fear/guilt subsystem appears to have been selected for and evolved as a way of trying to control these violent impulses. Yet, despite the reward/punishment effects of this system, which have considerable influence on consciously directed behavior, human tendencies toward violence remain very strong and untamed.

All in all, it appears that the emotion-processing mind is one of nature's most poorly evolved systems. Once the human mind had acquired language, the situation spun out of control. Human ingenuity for causing harm to others and conscious system overload ran far ahead of the capabilities of the human mind to cope with the complexities of human life. The process of natural selection lagged far behind social change so that minds became less and less able to deal with more and more stress and trauma.

Because evolutionary processes take place at such a slow rate of change, it now falls to evolved human creativeness to find ways of helping the human mind to adapt more effectively to present-day, emotionally charged impingements. And psychoanalytic theory and practice will be able to contribute to these desperately needed psychological advances only when its practitioners overcome their own natural, denial-based defenses so they're able to more accurately and non-defensively understand the human mind and its operations. On this basis alone will they be able to help forge positive changes in the emotion-processing mind and in the human condition. 


\section{References}

Bickerton, D. (1990). Language and Species. Chicago: University of Chicago Press.

Corballis, C. (1991) The Lopsided Ape. New York: Oxford University Press.

Cosmides, L. \& Tooby, J. (1992). Cognitive adaptations for social exchanges. In: Barków,

J., Cosmides, L. and Tooby, J. (Eds). The Adapted Mind. New York: Oxford University Press, pp. 163-228.

Donald, M. (1991). Origins of the Modern Mind. Cambridge, MA: Harvard University Press.

Gazzaniga, M. (1992). Nature's Mind. New York: Basic Books.

Langs, R. (1996a) The Evolution of the Emotion Processing Mind. With an Introduction to Mental Darwinism. London: Kamac Books.

- (1996b) Mental Darwinism and the evolution of the emotion-processing mind. American Journal of Psychotherapy, 50: 103-124.

- (1997) Death Anxiety and Clinical Practice. London: Kamac Books.

- (1998) Ground Rules in Psychotherapy and Counseling. London: Kamac Books.

- (1999). Psychotherapy and Science. London: Sage Publications.

Liberman, P. (1991). Uniquely Human. Cambridge, MA: Harvard University Press.

Maidenbaum, A. (1998) Dreams and other aspects of Jungian psychology. In R. Langs (ed.), Current Theories of Psychoanalysis. Madison, CT: IntemationalUniversities Press: 227-254.

Mithen, S. (1996) The Prehistory of the Mind. London: Thames and Hudson.

Plotkin, H. (1994) Darwin Machines and the Nature of Knowledge. Cambridge, MA: Harvard University Press.

Slavin, M. \& Kriegman, D. (1992). The Adaptive Design of the Mind. New York: Guilford Press.

Tooby, J. and Cosmides, L. (1990b) The past explains the present. Ethology and Sociobiology, 11: 375-424. 